\section{Recent Solar Activity and Radio Fadings}

Among the recent solar phenomena, now betokening a considerably disturbed sun, may be noted two large groups of sunspots and a smaller one of special interest. Particulars of these groups are as fellows :

\begin{tabular}{|c|c|c|c|}
\hline $\mathrm{Da}$ & $\begin{array}{c}\text { Central Meridian } \\
\text { Passage }\end{array}$ & Latitude & $\underset{\text { Area }}{\text { Maximum }}$ \\
\hline Ja & January $24 \cdot 2$ & $19^{\circ} \mathrm{S}$. & 1500 \\
\hline 19-Feb. 1 & January $26 \cdot 1$ & $20^{\circ} \mathrm{N}$. & 600 \\
\hline January 24-Feb. 6 & January $31 \cdot 2$ & $11^{\circ} \mathrm{S}$. & 1500 \\
\hline
\end{tabular}

Areas are expressed in millionths of the sun's visible hemisphere.

Group (1), although of considerable size on January 19 , declined rapidly after a few days and by January 27 had shrunk to less than 200 millionths in area. In association with group (2) an extensive bright $H \alpha$ eruption occurred on January 27 between $10^{\mathrm{h}}$ and $12^{\mathrm{h}}$. This eruption was recorded on hydrogen spectroheliograms taken by Mr. Evershed at his private observatory at Ewhurst, Surrey; at Greenwich it was cloudy at the time. The first spectroheliograms, taken at $10^{\mathrm{h}} 36^{\mathrm{m}}$ and $10^{\mathrm{h}} 46^{\mathrm{m}}$ U.T. respectively, show a patch of strong $H \alpha$ emission at a position $22^{\circ} \mathrm{N}$. and $23^{\circ} \mathrm{W}$. of the sun's central meridian; at $10^{\mathrm{h}}$ $55^{\mathrm{m}}$ the eruption was still present, but at $12^{\mathrm{h}} 7^{\mathrm{m}}$ when the last spectroheliogram was taken the eruption had almost faded from view. The beginning of the eruption, normally very sudden, may therəfore be placed at some minutes earlier than $10^{\mathrm{h}} 36^{\mathrm{m}}$, and the ending, usually much less definite, at about $12^{\mathrm{h}} 10^{\mathrm{m}}$.

IT is interesting to record that a radio fading on short-wave wireless transmission was reported to have occurred at the same time on January 27 from $10^{\mathrm{h}} 25^{\mathrm{m}}$ to $11^{\mathrm{h}} 50^{\mathrm{m}}$. A passing comment may be made on the fact that bright solar eruptions, associated with fadings of short-wave radio transmission over daylight channels, occurred at 27-day intervals on December 30 and December 3 last (see Nature, Dec. 12, p. 1017 and Jan. 9, p. 61). Furthermore, this apparent 27-day sequence is carried back still further by the recorded radio fadings on November 6 and October 9. The requisite international solar data are not yet published to see whether bright solar erup. tions were observed at the time of the radio fadings on the last two dates. At the time of going to press, it is reported from the Royal Observatory, Greenwich, that the third group of the above list has increased greatly in size, and on January 31 it was about 2500 millionths of the sun's hemisphere in area. The group is likely to be the largest recorded since 1928.

\section{Recent Crystallography}

IN his Friday evening discourse at the Royal Institution on January 29, Sir William Bragg discussed recent work in crystallography. When X-rays were first applied to the determination of crystal structure, the forms examined were naturally those of simple design. As the technique improved, and as insight was gained into the modes of construction of which Nature made the most use, it became possible to attack more difficult examples with success. Quite recently, the X-ray methods have been able to give material assistance in the examination of the complicated bodies which play the leading part in the living organism, such as the proteins. X-rays have the special power of discerning regularities in the arrangement of the atoms and molecules of which substances are built. Until they were applied to this purpose, no one had suspected how usual and fundamental such regularities were. Nature's structures are generally based on the repetition of some unit of pattern. Even a very small crystal is formed of the orderly repetition of some atomic design repeated billions of times: and the minute but ubiquitous proteins of all living organisms possess this ordered arrangement though they are far too small to be seen in the microscope.

The proteins all have the same basic composition. This again is an instance of the remarkable limitation to a few fundamental and elemental designs which is characteristic of the natural world. Every protein is composed, in the first instance, of a long chain in which two atoms of carbon and one atom of nitrogen form a pattern of three links, repeated throughout the whole length. Pendants of several varieties are attached to this chain, and one protein differs from another in the nature and variety of its pendants. The work of Astbury and others has shown the details of the construction of the proteins which make up the fibre of wool and hair and horm. It appears that in some substances, such as the un. cooked white of an egg, the protein chain is coiled up into the form of a ball. Quite recently, Stanley, of the Rockefeller Institute, has been successful in isolating what is almost certainly the virus of the tobacco plant disease, and showing that it is a protein. This is most remarkable since the virus, by some means or other, is capable of multiplying itself. Bernal and his collaborators have shown that it is crystalline, and have used the $\mathrm{X}$-rays to measure the regularities of its construction. It is of enormous size, relatively to the usual molecular dimensions, having a molecular weight of about twenty millions. It is needle-like in form. It has the optical properties of a crystal. This remarkable combination of properties is probably to be found in other forms of disease-producing virus, and the new discovery may well prove to be of the greatest importance.

\section{Germany and the Nobel Prizes}

During Herr Hitler's speech to the Reichstag in the Kroll Opera House, Berlin, on January 30, it was announced that he had issued a decree forbidding Germans to accept any Nobel Prize in future. This decree has been issued to avoid repetition of "shameful events of the past", which presumably refers to the award of the Nobel Peace Prize last year to Herr von Ossietzky, the German pacifist. The decree has been received with resentment in Sweden; but the Swedish Nobel Committee looks upon it as Germany's loss, for, since 1901 (when the first prize was awarded), nearly one quarter of all the Nobel prizes have been awarded to German citizens, and during the past ten years twelve out of the forty-one

(Continued on p. 241.) 